Kohl: a Journal for Body and Gender Research

Vol. 3, No. 1 (Summer 2017)

\title{
Institutional Migrations and Radical Survival: Beyond Organizational Splits
}

Gholama, Zakaria, Amira, Sama, and Mawn

Edited by Ghiwa Sayegh

This recorded conversation between Lebanese feminist activists living in Lebanon was held on the $18^{\text {th }}$ of June of 2017 and lasted for three hours.

This group of feminist activists came together in an attempt to historicize their personal and political frustrations. The scope of this conversation covers recent events in the LGBT and feminist movements in Lebanon. The discussion was prompted by the silencing and dismissal of debate around Beirut Pride in 2017; yet, it revisits queer and feminist contemporary history in Lebanon and thinks through gender and gay mainstreaming, NGOization, funding, accountability, and stagnant leaderships. In this sense, rather than indicating historical shifts of alliances and people across groups and organizations, institutional migration becomes a necessary structural process that radically resists the NGOization of movements and the cooptation of women and trans within both the LGBT and feminist circles. 
Mawn: $\quad$ As soon as something gets divided in queer or feminist communities, or something branches out, people feel it jeopardizes the integrity of the original project, instead of seeing it as different versions of it or different approaches to it. Things divide or break down because they do not work for the same end, but the reception shows no absorption to plurality. Instead, people seek to cover up whatever divisive issues they have. And this is a big problem because you can never pretend then that there is a consensus.

Gholama: When we stay under one flag, we have to find a compromise, and this compromise is always at the expense of women and trans. We are always told that now is not the appropriate time, because there is a certain attack, a certain crisis, a certain momentum. Personally, I do not remember a time when we were not living a crisis. What does it mean when we rally under one flag? It also means we are rallying under one leadership, one identity. Not only does this one identity obscure other approaches, but it also makes them illegitimate and capitalizes on the power of representation. Why do we have to gather if we do not have something to gather under? This is similar to how we leave our families. We do not have a healthy process of moving out of the family's house outside of heteronormative marriage. It is either because the family is khara, ${ }^{1}$ or the daughter is a sharmouta. ${ }^{2}$ That's it. This is the dynamic that we replicate in our movements. People do not want to discuss intersectionality for example because we need to "prioritize," or work on the "essence." And at the same time, people tell us to work under their flag, work for them.

Amira: We experience realities in ways that are very different. And the notion of rallying under one cause is an oversimplification of the ways we are differently positioned. The concept of unity presupposes that we are working towards one end. But it is not simply about the end, it is especially about what we do, how we organize, how we build structures on the way to reaching that end. For instance, we have been asked over the past month to rally to fight for a "society" that is not homophobic. Not only can a society not be treated as a homogenous entity, but non-homophobic societies can be neoliberal, privatized, and oblivious to class issues to the extent that a non-homophobic society would be a society for the rich.

Mawn: $\quad$ And this illusion that we have of a common end is brought home by the fact that we are always asked to respond to "a common evil." When there is a common evil, it creates the illusion that we all work towards the same thing. And no, just because we are against the same thing in principle does not mean that we need to be absorbed by this homogeneous entity.

1 Shit.

${ }^{2}$ A derogatory term for sex worker in Lebanese dialect, also used as a generic insult directed at women. 
Kohl 3.1

Zakaria: Has anyone noticed how patriarchy is being treated these days? The term "patriarchy" has been so mainstreamed and overused that people stopped looking at particular categories and how they are being alienated or oppressed. A word becomes the ultimate enemy.

Mawn: It is the same with liberalism, as a big evil, but it is not enough to have everyone under the same umbrella. And this creates the illusion that numbers alone, rather than discourse, can tackle those issues. We become tokens in numbers in the fight against a common evil.

Zakaria: If we are going to continue with the family metaphor, the "child" who says "this is not the kind of family I want to be in" becomes demonized. This is what happened with Helem ${ }^{3}$ and Meem, ${ }^{4}$ and keeps happening with any initiative that stops wanting to be part of an entity of cis gay men. In the case of the split between Nasawiya 5 and Meem, the "child" was disowned: "this is not the kind of child we want to have." The main motive for its creation became the reason behind its expulsion: that child was expelled for being queer. Nasawiya was created out of Meem because we needed a public entity. At some point, Meem was cut off and that separation was forced. So when is the separation intentional, and when is it about initiatives being disposed of because they mean nothing anymore? For instance, Salwa ${ }^{6}$ mobilized so many people; the moment funding was gone, it was no longer a priority.

Amira: When we consider that an entity or a project is out of a structure, it means that it is out of a structure that stands by its own. Why is the structure never out? The entity perceived as "out," "conflictual," or "divisive" is always the entity that has less power: power of leadership or resources, power in the "movement," power to coopt and coerce. Not only is the structure never out, but it reenacts the figure of the patriarch, despite it talking about patriarchy.

Gholama: Add to that, no matter what split happens, and regardless of the metaphorical blood spilled, the structure never questions itself or tries to understand the root causes of the split. Structural changes never happen as a result. If anything, more walls are erected, more restrictions are put in place, and they become framed as "preventive" measures.

Zakaria: Going back to the example of Nasawiya, because of the vagueness of the structure, splits become easily erasable from history. Then, those with the resources and the networks can pick everything up, even if they have to physically migrate. In that sense, Nasawiya stopped, but the structure was never reformed.

\footnotetext{
${ }^{3}$ Helem is an LGBT organization in Lebanon that was founded in 2004.

${ }^{4}$ Meem was an LBT support group that split from Helem in 2007.

${ }^{5}$ Nasawiya was a feminist collective that was founded in 2010; many of its founders were members of Meem.

${ }^{6} \mathrm{~A}$ multimedia project on sexual harassment that came out of Nasawiya.
} 
Gholama: The quarrels are either ethical or ideological or both, and when the group splits or part of it splits, no one tries to look at the structure of the original organization.

\section{Organizing Patterns, NGOization, and Mainstreaming}

Gholama: We have traditionally organized under two models. The first is what we call grassroots, such as feminists reclaiming and creating feminist spaces, or identity-based community organizing, or both. The second model is the typical NGO model, where we look for funding, hire employees, and rally people under projects. So if we are creating something based on the identity of people, then identity-based organizing is seeping into our activism, no?

Amira: $\quad$ Yes, but what happens when NGOs pretend to become movements?

Sama: I think the difference is between single-issue based organizing, which is done by NGOs most of the time, whereas spaces like Nasawiya and others that might have started as identity based do include multiple issues. How do you see NGOs trying to become movements?

Amira: $\quad$ We need to talk about NGOs the way we need to talk about NGOs, with a specific purpose like service provision, or a specific project that gets specific funding. Obviously, these purposes do fill a gap. But to conflate movements with NGOs means, by virtue of NGOs' access to resources, to acknowledge NGOs as leaders of "the movement." And I am using "movement" in singular because multiple-issue lives become sanitized under NGOization. NGO work is a type of activism, but it is not the only one. It should not be the only one. And the sanitization of the singular "movement" makes it impossible to challenge structures and funding. For instance, I am incredibly surprised that some feminist circles are no longer willing to challenge funding sources and hold those who claim to represent us accountable, at least in terms of their funding and its consequences.

Gholama: I do not think there was a particular will to challenge that in the past. What is different now is that the oppositions are individual rather than structural. Meem did not feel the same pressure because it was self-governed and did not respond to anyone, so it was not exposed to criticism. In my opinion, this discourse did not resonate with some feminist circles, including the people we knew and worked with, specifically because of the negative influence of feminism becoming identity-based. In some instances, feminism is no longer about the cause, but about representing feminists within gay circles, particularly in the age of gay mainstreaming and gender mainstreaming.

Sama: Let us remind ourselves that at least when I joined Meem, how we thought we were organizing was very different from the reality of how we were organizing. I thought we were a grassroots movement, very different from NGOs, and where decisions were consensus 
based. But then you start to understand that in some instances, this type of organizing has the form of an invisible NGO, that we do receive funding, and that we do have a to-do list, including the boring tasks of reporting to funders and bringing in money. I came to understand that if you want a space for queers, you have to work through those realities, regardless of how we name our organizing and structures. I think we need to acknowledge the similarities and overlaps between NGO work and what we called grassroots organizing.

Gholama: There are similarities of course, but I do think that there is a fundamental difference in structure. Most of the time, spaces that are membership-based include a physical space where the people we represent can come in and actually have access to it. Regardless of the dynamics and accessibility and accountability issues, spaces like Meem before and Dammeh ${ }^{7}$ now create an eco-system of public opinion. You have a certain legitimacy and a system of objecting. Even if you do not object through the structure, you are still objecting. It is an invisible form of objecting. Despite that, leaderships have been stagnating.

Mawn: As a result of that system you mean?

Gholama: I think it came hand in hand. But in general, leaderships are stagnant.

Mawn: $\quad$ And one could not object?

Gholama: How would you object? Through what mechanisms? For example, when Beirut Pride ${ }^{8}$ was happening, many had objections that were not heard because they came from non-activist circles, and most remained silent because they felt they were not directly involved with the organizing process. On the other hand, all the objections raised were singled out as attacks. There was no space where objections could be translated or transferred to the organizers.

\section{Being Absent from "the Ground" or Posing an Institutional Problem?}

Amira: We need to challenge the notion of who can speak and what constitutes activism. I feel that the discourse of "you cannot speak because you are not an activist" was particularly present in the context of Beirut Pride, and activism became restricted to that moment and to a prototype of participation and involvement.

Sama: It goes hand in hand with deciding who does work on the ground and who does not.

${ }^{7}$ Dammeh is a feminist cooperative that was founded in 2014.

8 Beirut Pride is a trademarked event that took place around IDAHOT in 2017. 
Amira: $\quad$ There definitely is an archetype of who an activist is, while the other instances of activism that are less visible, like the conversation we are having right now for example, are completely disregarded and dismissed as tanzir. ${ }^{9}$

Gholama: We do not have an understanding of what an activist is or what being on the ground is. Some activists engage in the traditional modes of "working on the ground." If that was the definition, then I would qualify. Yet, in the case of Beirut Pride, I censored myself and refrained from talking about my issues with this project. I censored myself because I do not want to damage the work of some organizations, specifically Helem. I do not want to fight them; I want to fight the system. At the same time, the label of "activists" versus "not activists" in the context of Beirut Pride had nothing to do with how much they have risked or in how close of a contact they have been with the community, or how many prisons they have entered.

Zakaria: Maybe we should redefine what falls under these from scratch. If it is about gender and sexuality, organizations like Kafa ${ }^{10}$ would have the opportunity to talk since what they do is work on the ground. But are people looking at that? The activists referred to are placed in a mold, but when it comes down to it, how are they measuring it? Is it about who goes to protests? Who writes more posts on social media? How much one reads? How much one publishes on Facebook? If we look at the measures of evaluation, they are very wrong. While labels like "queer feminist" are proliferating, and "trans" is thrown around anywhere, what really matters is whether there is a structure behind you or not. When you are part of something, you get invited to discussions, initiatives, and meetings; you get a certain legitimacy. But the moment you decide to criticize that balance, it becomes an institutional problem. It is as if you are waiting for your father to give you approval to speak.

Gholama: $\quad$ That is the problem; we are "allowed" to navigate certain spaces, but when there is an issue, we are asked to talk about it internally, but the issue never gets addressed from the roots. We know good examples of where that has led, like the gender issue at Helem, and the sexual harassment issue at Nasawiya that went unaddressed for 10 months despite people trying to talk about it. So if we look at Pride or Women's Day, all the objections raised are a decade old. I spent 7 years arguing for the same thing with the same people again and again. Am I supposed to keep saying "please listen to me; please don't be so male-centered; please don't be so citizen centered?" What about my labor in all of this? And then we are told that the only legitimate way to say these things is to talk directly to the same people. Where is the problem if I speak publicly?

\footnotetext{
9 Preaching or lecturing.

${ }^{10}$ Kafa (enough) Violence \& Exploitation is a feminist NGO that works to eradicate gender-based violence and exploitation.
} 
Kohl 3.1

22 Mawn: It is strange that these issues are not discussed publicly. I think the open discussion hosted by the Socialist Forum ${ }^{11}$ about Pride was the only time I heard of an open discussion of the sort.

Zakaria: But what do "open discussion" and "public" mean? There is an assumption that Facebook is a public platform. On a recent status I posted, I was called out for not having a public discussion about my gender, and for my usage of whatever word I am using to refer to myself, sous-pretext that Facebook is a public space, and when you publish something it is like you are opening it for discussion. Expressing an objection should not be done through Facebook alone. And that open discussion was not public - we heard about it by invitation. So when you want to have a public discussion, whom are you making it public to? And often times, when certain people are there, others are completely censored. Dynamics do shift.

Mawn: I think the people who attended the open discussion were very specific kinds of people. You could have people who agree and others who do not, or you would have a homogeneity, but you will not have variety, whereby people who are outsiders are witnesses. When you have witnesses, you cannot attack someone on something that is personal. "Public" is layered.

Zakaria: But usually when you do something open, people self-select, and eventually witnesses disappear.

Sama: I lso have a problem with people seeing these issues as ideological or intellectual, as if we do not have a decade of history together. If I criticize something and get indirect responses on public platforms, as if I am not worthy of being directly engaged with, this is an erasure of that history. People we have a history with know whether I am on the ground or not, or in a movement or not, and for what reasons. They know how much khara there is that would make me decide not to be part of a movement - things like Beirut Pride make me want not to be part of a movement. We worked together on a day to day basis, had coffee together, talked politics together - they even know about my heartbreaks. Then they pass over me and write things like these? And then pretend that they have had an open discussion? It is not okay. This is not okay, the way we treat each other is very significant to our movements' health.

Zakaria: There can be no claim about you not being on the ground, especially when you go back in history. You do not and cannot only talk about the moment "now," but about things that have happened before and that you have experienced as an activist. The "on the ground" question is then futile. If I am part of a movement, I cannot talk about it unless I am visibly organizing right now, at this precise moment in time? For me personally, other than expecting tokenization because I address the trans issue, do I get to talk about that past? I think from

11 The Socialist Forum is a feminist leftist political group founded in 2010. 
what I gather today is that you're not supposed to talk. Then many ask where the strategies are if we open any conversation. Only few are talking for there to be any strategy, and work is constantly appropriated and/or ghettoized. There is this constant need to know what you are doing "on the ground." So if I help a friend with emergency response, is it considered that I have done something "on the ground?" This type of labor is service provision and aid.

Amira: I think in my reading of Beirut Pride specifically, "on the ground" was not to be physically present, but about a "sense of duty" at this moment of time to stand in "solidarity" with either Pride organizers or NGOs.

Gholama: $\quad$ The same way we ask what is being on the ground, we can also ask what solidarity is. What is the solidarity they were expecting? I personally did help and had no problem doing so. But was I legitimate? Was I "on the ground?"

Amira: $\quad$ So, what does it mean?

Gholama: $\quad$ We are put in a situation where we are asked to support, help, and turn a blind eye towards the problematics and our criticism of Pride. And criticism of Pride is not the same as criticism of the NGOs - I have different criticisms for both; yet, if I am critiquing Pride in this instance, then every leader or every figure of an organization feels personally targeted. And when people are challenged to define what they mean by "on the ground," they escape the question. On the ground is very clear: it is whether or not you are working grassroots working with the community, making activities for and by the community. On the ground would also be the social workers who are managing cases, administering aid, or creating support networks that, for instance, do not involve the CEOs.

Sama: $\quad$ There is also the activist tag, or taking up the persona of an activist, and just being very loud about it and about what you think all the time by, for example, showing up to different events, which is also seen as being involved on the ground.

Gholama: That is not even the definition of being "on the ground."

Sama: $\quad$ Clearly, but this is one of the perceptions of someone who can legitimately say things if they want to. As for NGOs that do service provision, the idea is not that it is work that should not be done, but that it is incomplete. In a lot of ways, it was done in very misogynistic ways. And in a lot of ways, it was also necessary, especially when it comes to the services offered by Marsa, ${ }^{12}$ Helem, or MOSAIC ${ }^{13}$ now. In the past, my hope had been that we were building our own feminist and queer movement, however we define that and in the broadest of ways,

${ }^{12}$ Marsa is a sexual health center that has been operating since 2011.

${ }_{13}$ MOSAIC is a regional human rights NGO that focuses especially on LGBTQI rights. 
Kohl 3.1

but that didn't really work out. At the same time, we cannot be in a movement that works with the police, like Kafa or Helem. I would rather be present in movements that think of what we can do without the police.

\section{Movements, Funding, and Leaders: What Accountability?}

Amira: I have a feeling that being able to call yourself a movement and receiving support for it is a place of privilege. Building something around service provision is not a movement by its own, and yet, it is being called as such. Ultimately, it is about who has the authority to name themselves. And this brings me to the question of who is worthy of solidarity. Has it ever been queer women?

Zakaria: Most of the feminist events are happening under the academic side of the discussion about us/them. But is the us/them binary shifting?

Amira: I do feel that the problem is mostly with being asked to be "grateful" to be given a space, even if that space is elitist, neoliberal, and funded by state departments. Some feminists are adopting an apologetic discourse when it comes to this type of organizing, and if this is not mainstreaming, I don't know what is. I do think it is possible to challenge from within - I am not saying otherwise, but challenging from within would also entail shaking structures from their foundation instead of giving them legitimacy. The counter-argument is to keep asking where the "alternative" is, and that doing "something" is better than nothing. But there is no alternative specifically because these spaces remain unchallenged. Any dissenting voice is made to feel systematically isolated, whether resource or support-wise. Instead, NGOs and initiatives run towards funding, and silence others by accusing them of not doing anything.

Zakaria: It also has to do with leadership positions and gatekeepers. If you are on good terms with LGBT or feminist "leaders," or people who have been historically assigned to that role, then you are more likely to get funding or meet someone who would sponsor you. The leadership and spaces who have access to resources, including human resources, are rarely ever held accountable. And on paper, there is a lot of work happening in Lebanon, so funding becomes restricted to the same groups and leaders.

Sama: $\quad$ And when you go to international conferences and spaces, you will find the same people representing and talking about their work and strategizing.

Zakaria: But who is representing and talking? If you go to conferences and meetings, there are people who are put under the fire, not more. We are facing active cooptation between the LGBT and feminist movements to erase history, because it worked much better for the people in historical leadership positions in 2007, when nothing else was happening in Lebanon. 
Amira: I find having the power to change the funding agenda in the region to be very dangerous, but I do not think that feminists are included and/or heard in those spaces, particularly when it comes to funding. Inclusion is conditional; it entails not being a troublemaker and be coopted into the structure. Feminists are "included" superficially as proof of openness and inclusion, but not to actually change anything. The moment that you dig deeper than that, you're out.

Sama: $\quad$ At some point, the funding sphere has shifted. Funders were interested in smaller groups on a national level, initiatives that are grassroots, and they were willing to be "bold," like with Meem or Nassawiya. But then they started wanting to fund the region, so they privileged organizations that were able to work on a regional level and put all their funding there instead of dividing it among smaller initiatives. And feminists of course need to find jobs, do labor for these organizations, including emotional labor, and then realize at different moments in different ways that this does not work. People keep dropping out, yet it keeps happening. The particular reality that leads people to make different choices hasn't changed.

Gholama: $\quad$ But this is a global feminist problem: that feminists are constantly working for human rights or within LGBT organizations. Is it even possible to work on a grassroots level right now? These are our personal migrations as well; we were chewed up by NGOs, and they deformed our skills. For many of us, the finality is to get to academia, but our only set of skills is NGO development and there are only a few ways that this could be done, like through service provision, or violence against women work, or report writing. And with the shrinking of the funding, I cannot think of groups that have sustainable structures that are accountable to their communities.

\section{Beirut Pride and Depoliticized "Positivity:" What Solidarity?}

Zakaria: $\quad$ You cannot talk about where the queers are investing their time and where they get their money and that kind of critique without looking at who has the ability to do so. Who is staying at home and can work and be an activist, without having to make difficult choices? There are a lot of privileges involved. And at the same time, there is a lot of critique about positionality. When Beirut Pride happened, representation was a word that was repeated a lot, particularly when it came to the NGO involved. Who are you to come represent us? Who are you to coopt?

Gholama: The main concern was the history.

Zakaria: $\quad$ Yet, when things are flipped, it is very funny that it is the same critique and no one notices that. 
Kohl 3.1

Amira: I think there is a qualitative difference. I do not know if you remember the discussion, but NGO representatives kept arguing on social media that they cannot forbid anyone from listing their events - that they were randomly listed.

Gholama: This came at a later stage.

Mawn: What do you mean by listed?

Gholama: It was not clear what Beirut Pride was, whether they sat and agreed on the events, or whether these events were going to happen anyway then were listed under Beirut Pride's calendar. So the recurrent discourse was that it was just a calendar, when Pride organizers had actively reached out to make events for gayness. And of course, the big elephants in the room, such as the problematic position of Proud Lebanon, were completely absent from the discussion. In fact, those elephants were being normalized. There is no logic and there is no common sense in the discussion, and this is why there was no defending statement in writing. There was a written response to the Socialist Forum's statement only because it criticized the structure, but still, the reply was very broad.

Mawn: $\quad$ And from what I have seen, everything was framed as positivity, and criticism was met with accusations of raining on someone else's parade, preventing unity, and smearing good intentions.

Sama: The media coverage was also horrendous with headlines about it being the first pride in the "Arab" world, implying that the "Arabs" are now civilized.

Mawn: $\quad$ One of Pride's hosting spaces' response to all of that was basically "we have a space but we have nothing to do with what happens in this space." Criticism was dismissed as "negativity" in opposition to "positivity." At the same time, the call to the drag workshop that was completely out of context invited people to go and have a laugh. How can one be this disengaged from what happens in their space?

Zakaria: Solidarity becomes about being in solidarity with individuals.

Mawn: It goes back to the liberal thinking of accepting a certain degree of diversity that is very controlled or selective until it hinders your work. Amira gave the example of accepting feminists as long as they compromise on some of their political views where they conflict with theirs. Otherwise, of course you become a problem and we will not speak about you. 
Zakaria: That is the case with feminist spaces where you check class at the door, with the illusion of all being "equal" in the sense that we are "women" and working towards the same struggle. We are asked not to be different, not to show that difference.

Sama: $\quad$ Even when Helem works with the police, they know that it is a compromise; they have to do it so that people on the inside can have a minimum of protection. Beirut Pride was totally oblivious to the problematics of the police.

Gholama: Not only did Pride organizers thank the police, but they also registered Beirut Pride as intellectual property as I found out during the discussion hosted by the Socialist Forum. It doesn't sound to me like someone who is "experimenting." They are making a business out of it. And therefore, there is no reason for us to be complicit in it. The biggest issue with gay mainstreaming is turning it into a festival. The same goes for International Women's Day. We are at a transitional point where people are eager to show that they are not homophobic, but they are doing so by tokenizing. Beirut Pride's insistence on rewriting history and the complicity of organizations that rewrote history alongside it have been quite damaging and dangerous. Besides, in terms of representation, the media repeatedly quoted two highly problematic figures that suddenly became international representatives of the "movement." We are too busy fighting the system. I therefore cannot engage with all the organizations I criticize. And I refuse to be engaged with Beirut Pride, it is not a thing. There is a fundamental problem when someone says they have no issue with the law, when they don't want to change anything, when they thank the police for protecting us as "Lebanese citizens." What does that mean when half of the country's residents are not citizens? What does that mean when the whole NGO LGBT sector is living off the funds that come for Syrian LGBTs? Do we not object to anything because we want to fight the Association of Muslim Scholars? I see us as complicit; just like the Association of Muslim Scholars and other conservative groups, we contributed in increasing the capital of Lebanese citizens and fucking the rest over. And that is why we were both thanking the police.

Mawn: If there is anything local about the Pride, it is its context. They took the crème de la crème of everything that is messed up here, like centering the event on citizenship and gay men, making it a celebratory party that refuses to work on anything meaningful, and getting away with it. What are we doing? Where is the solidarity in this?

\section{Institutional and Structural Migrations: On Inclusion and Survival}

Zakaria: If I want to link my work to a movement, it would probably be closer to the feminist scene. But at the same time, what would happen if we criticize feminist work as feminists? This is something that is unspoken, like the tokenizing of migrant domestic workers' during International Women's Day. 
Kohl 3.1

Gholama: If you criticize feminist work, especially this kind of work, you will probably be just ignored.

Zakaria: $\quad$ Ignored is much worse.

Sama: I think that is what would happen though, you would be ignored.

Gholama: I think there is a structural difference between feminist organizing and LGBT organizing. If we criticize some feminists, they will ignore you unless you create a momentum rallying a lot of people. That would be the reaction of the leadership. For instance, did they say anything about Beirut Pride? How many people are criticizing Pride?

Zakaria: There are things that were written though.

Gholama: Yes, but the reply of Helem to criticism is gone on their website. The articles that were published in Bekhsoos are not indexed, and they cannot be found on Google. These conversations need to happen somewhere outside the circles and on different platforms, not within these same organizations or on the Facebook profiles of specific individuals. And they need to be done locally, because other conversations are not relevant to even the mainstream society in Lebanon, whether political fights within feminism, or political fights within LGBTs. They are not relevant and they are not written in an accessible language, and you cannot mention an incident because it looks like you are just attacking people. So what do we look like for the actual audience that we want to reach?

Zakaria: But it is also important to have these conversations internally. The same fuss that is happening about LGBTs can happen about feminism.

Mawn: $\quad$ There is another structural distinction between establishing clear goals and claiming to reach everybody out there. So are the organizations we are criticizing reaching their goals or not, and in what ways? I think this is very different from questioning the goal itself. What is problematic is when you say that you are doing something when you are not.

Amira: $\quad$ It is like when you say LGBT and you mean $\mathrm{G}$.

Zakaria: Or when you say women and trans and you mean cis-women. This is the conversation I want to have and this is the struggle I want to speak of. In gay spaces, lesbians are systematically marginalized. But the same goes for feminist spaces, where trans is included arbitrarily. So if I feel I do not fit in a space, why am I still being invited? What gay spaces mean by trans is transfeminine individuals. What feminist spaces mean by trans is transmasculine individuals. What is the point of being so inclusionary when the reality is very different? Meem was open to trans people, but were trans people comfortable there? No. 
Did they feel it was a space for them? No. The same applies to Helem. Is there a single trans person that goes to Helem and does not come out complaining? Is the point of inclusion to look good? Is it because your friend is trans? Is it because you have funding for trans people? And then you have institutions that fund women and trans without clarifying what they mean by trans. We are very identity based. When you say women, you are talking within an identity. But when you say trans people, then you are talking about groupings of identities and different performances, all thrown under one umbrella. Is there a trans-specific compromise?

Gholama: When some say women and trans, they only mean the exclusion of cis-men.

Zakaria: We constantly call for justice, but we do not think of what it means. If we forget our fights, we are undermining our fights. We are taking for granted certain political positions. The leadership wants "peace" and things to work out, but they maintain the same behavior. Maybe if we start looking from there, we will start organizing differently, challenging gender, and working a little against our instincts. And this is why we migrate institutionally. When you push people out of spaces, you are putting into motion a process of constant migration on the institutional level. Why do people migrate?

Amira: $\quad$ To survive.

Zakaria: The day we decide that we will no longer work in the NGO scene, it would be both a personal and institutional challenge. 